\title{
SPRAY FORMING AND POST PROCESSING OF SUPERALLOY RINGS
}

\author{
Michael Walter ${ }^{1}$, Martin Stockinger ${ }^{2}$, Johann Tockner $^{2}$, Nils Ellendt $^{3}$, Volker Uhlenwinkel ${ }^{3}$ \\ ${ }^{1}$ Bohler Edelstahl GmbH \& Co KG \\ ${ }^{2}$ Bohler Schmiedetechnik GmbH \& Co KG \\ ${ }^{3}$ University of Bremen
}

Keywords: Spray Forming, Hot Isostatic Pressing, Forging, Microstructure Evaluation

\begin{abstract}
Spray forming as a technology to produce near net shape components or preforms for additional forming operations with defined microstructural properties is well known for several alloys and applications. The production of spray formed superalloy rings made of IN718 and U720 for aero engine components in order to reduce production cost is the goal of the current EU-research project. Several spray runs were carried out at University of Bremen to optimize the process parameters regarding a low porosity, low segregation and a high yield. Macro and microetchings were prepared to analyze the influence of the parameter variations on before mentioned structural properties. Several optimized rings were used to examine the influence of thermomechanical processing on porosity and microstructure of spray formed superalloy rings. Hot isostatic pressing and forging processes were performed separately as well as in combination in order to obtain the ideal post processing route, which was determined via microstructure analysis. As a result of this project, it became clear that HIPping is an integral part of the postprocessing of as-sprayed material, due to the fact that it was not possible to produce as-sprayed material without porosity. The development of micro- and macro structural properties through all these processes and their variations will be shown. Another paper presented here will focus on the final properties and applications of this material.
\end{abstract}

\section{Introduction and overview}

Spray forming as a method to produce fine grained preforms with low macro-segregations is based on developments by Professor Singer in the early 1970s [1]. As a result of several research activities of Singers group at the University of Swansea UK the company Osprey Metals was founded to further develop the process to an industrial standard. Since then several research programs have been started to optimize and test spray forming for different alloys and shapes e.g. [2-6]. In comparison to the conventional VIM, ESR, VAR cast and wrought route as well as to the typical powder metallurgical process spray forming offers the possibility to reduce several operations. That results in a saving of material yields, energy consumption, inventory and therefore costs to produce near net shape preforms. [4]

One of the main goals of this current research project was the optimization of spray forming for the nickel base superalloys IN718 and U720 as well as to find the best post processing route to produce turbine components with very good mechanical and physical properties. About 30 rings (inner diameter $340 \mathrm{~mm}$, thickness $60-80 \mathrm{~mm}$ ) were sprayed in three main experimental runs on a single atomizer facility at the University of Bremen [7]. A variation of different thermomechanical processes including hot isostatic pressing (HIP) and forging were obtained on the optimized and pre-machined rings to find out the ideal processing route (Fig. 1) and parameters. Macro- and microstructure evaluations as well as porosity investigations using 
digital image analysis have been carried out to quantify the quality of the different post processing routes.

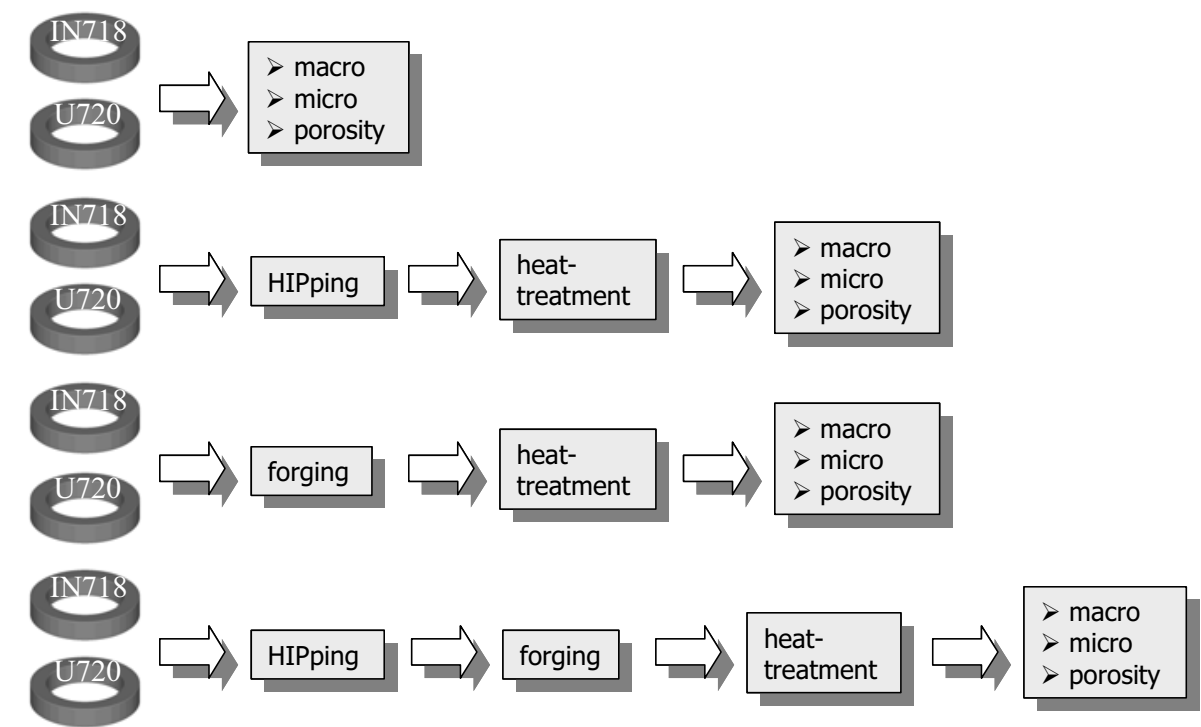

Figure 1. Overview of the different post processing routes

\section{Processing of spray forming trials and Evaluation of as sprayed structures}

The experimental spray forming program can be divided into three major phases: first deposition trials, systematic variation and constant repeatability. The first deposition trials where carried out under strongly varying parameters like average melt flow, atomizer gas (nitrogen or argon), and gas flow to get first impressions of the complex dependences of this process. The used equipment and parameters at the University of Bremen are well described in [7]. The substrate was heated by an induction coil placed inside the substrate to avoid high porosity in the vicinity of the substrate. The results of the first trials showed clearly that nitrogen as atomizer gas leads to high nitrogen pick up to 500 in the deposit with following shifts in the precipitation behavior, like strong amounts of nitrides and lowered gamma prime volumes, which at the end would lead to poor mechanical properties (Table 1). The disadvantage using argon for atomization is the higher porosity in the as-sprayed material because argon is inert gas. With nitrogen lower porosity is possible because the nitrogen is not inert and reacts with some alloying elements and builds nitrides or carbonitrides / Quelle: MG Benz, TF Sawyer, WT Carter, RJ Zabala, PL Dupree: Nitrogen in spray formed superalloys. Proc. Int. Conf. On Spray Forming, ICSF-II, Swansea, UK, Sept. 1993

Table 1. Chemical analysis prior to pouring and after spraying under $\mathrm{N}_{2}$ and $\mathrm{Ar}$

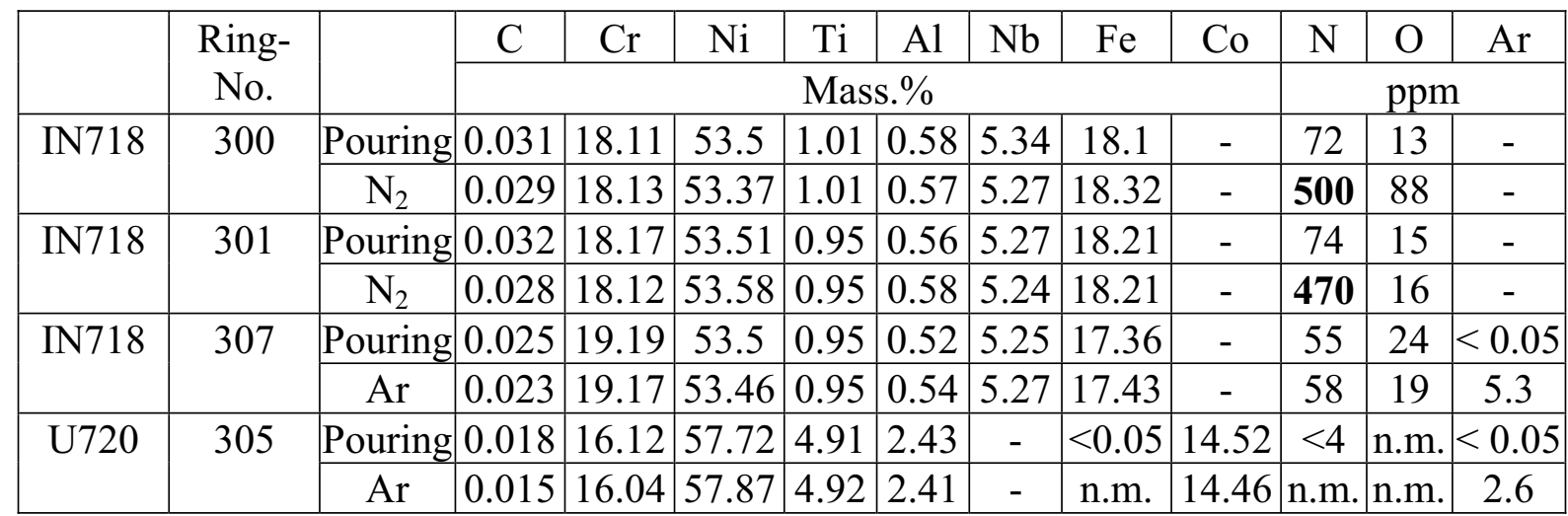


So, the decision was made to continue only with argon as atomizer gas. The evaluation of the rings contained a full cross section macro-etching sample, which was further used for shape measurement, porosity and micro structural examination and for chemical analysis. The porosity and micro structural examination was carried out on a sample from the midsection. The porosity was measured using microscopy and digital image analysis on polished specimens. Every black spot larger then $1.1 \mu \mathrm{m}$ was determined as a pore. The macro structures of the first deposition trial varied from rings (306) with extreme layered structures with higher porosity up to $15 \%$ to rings (307) with macroscopically segregated areas with lower porosity around $1 \%$ (Fig. 2).

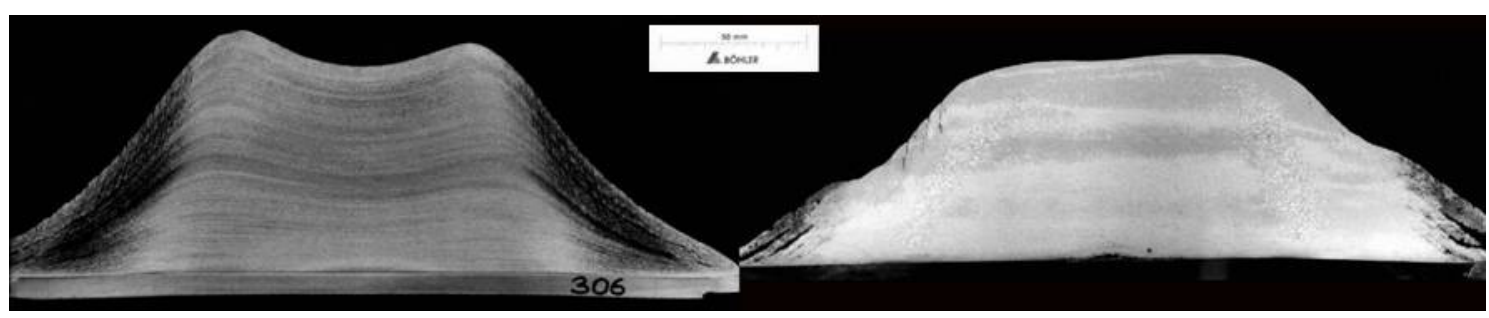

Figure 2. Macro etching of ring 306 -average deposit surface temperature: $1192{ }^{\circ} \mathrm{C}$ (left) and 307- average deposit surface temperature: $1291^{\circ} \mathrm{C}$ (right)

With the variation of the melt flow and achievable deposit temperature the main drivers for the solidification where found (Fig. 3).

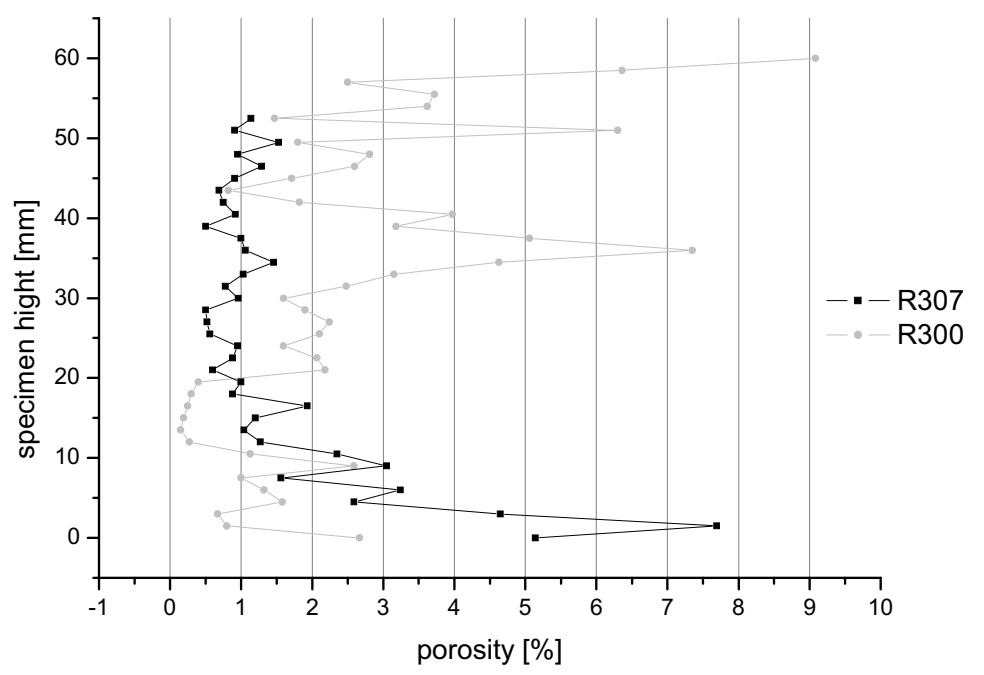

Figure 3. Porosity over spray height

of ring $300\left(\mathrm{~N}_{2}\right)$-average deposit surface temperature: $1230{ }^{\circ} \mathrm{C}$ and 307(Ar)- average deposit surface temperature: $1291^{\circ} \mathrm{C}$

The second phase of the experimental program was defined through the systematic variation of the melt flow and deposit temperature (see figure 4) to find the best solidification window. 


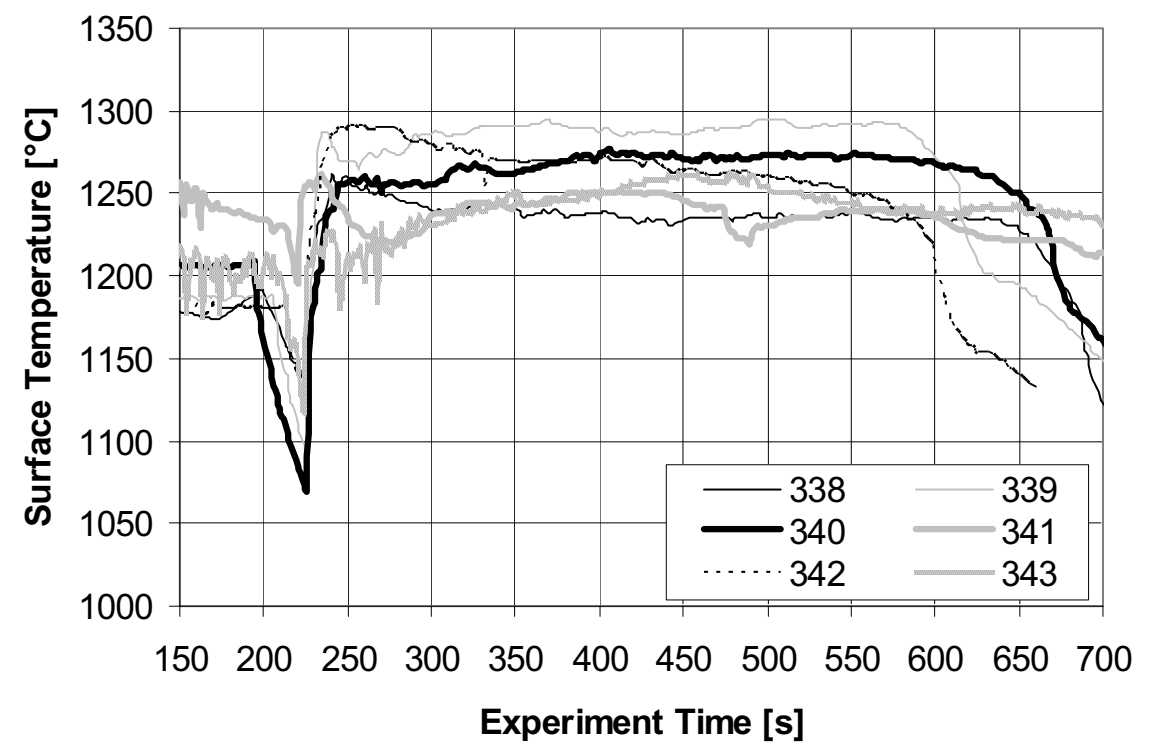

Figure 4. Deposit temperature variation trials

Investigations with other base metals have already indicated that the deposit surface temperature during the spraying process is the key parameter concerning the porosity [8]. Therefore, the measured deposit surface temperature was plotted against the local porosity in fig. 5. A low deposit surface temperature caused a high porosity (cold porosity) and a minimum porosity was observed in temperature range between 1240 and $1270{ }^{\circ} \mathrm{C}$. The deviation of the porosity at a constant surface temperature may be induced by other parameters but this could not differentiated. Finally, it can be established that the deposit surface temperature is the most important parameter to control the porosity. [7]

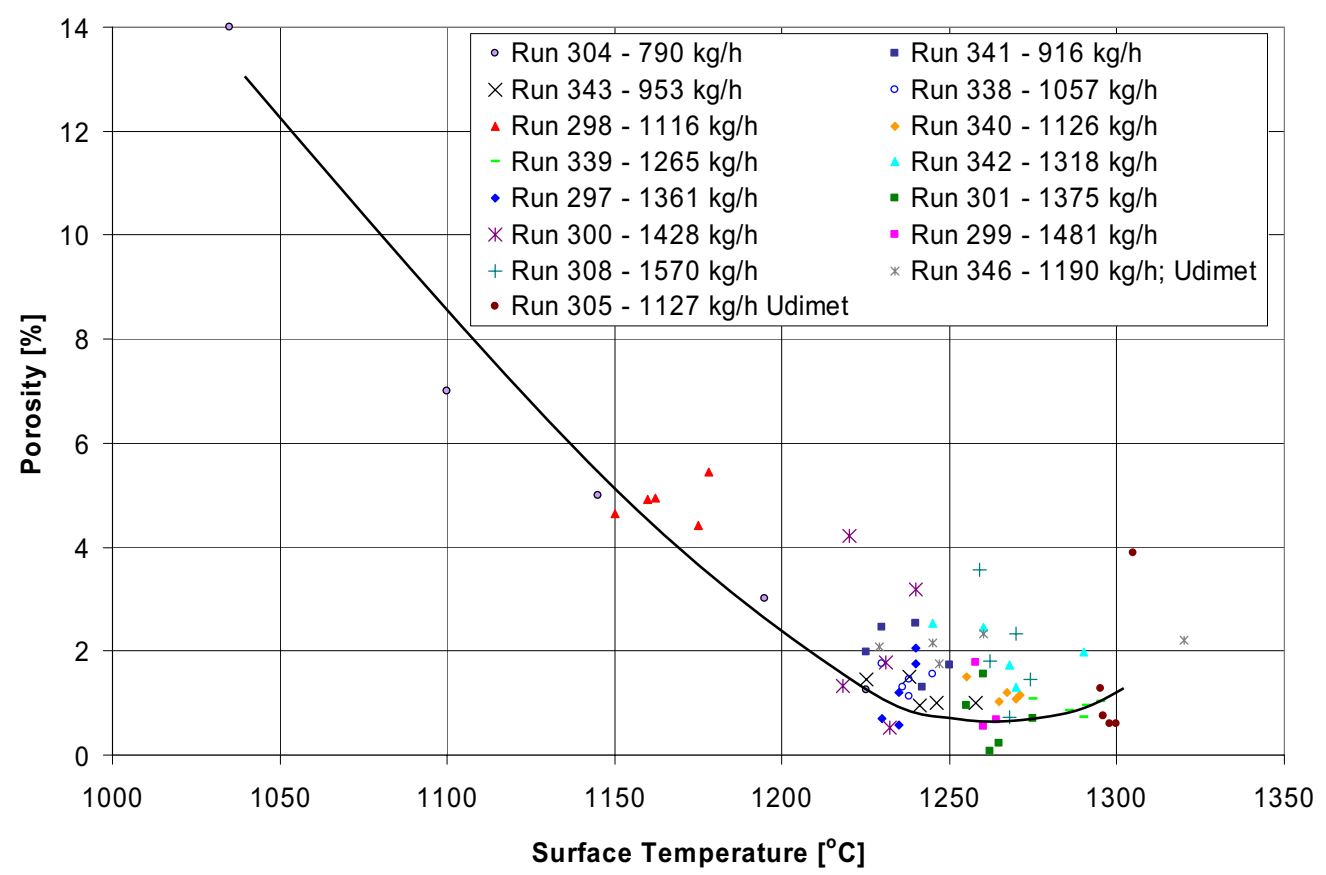

Figure 5. Dependency between local porosity (buoyancy method) and deposit surface temperature of spray-formed rings (IN718 and U720 using argon or nitrogen), melt flow is given in the legend

Again the macro and micro evaluation was made and the best structure (340) was chosen for the third phase of the experimental program (Fig. 6). 


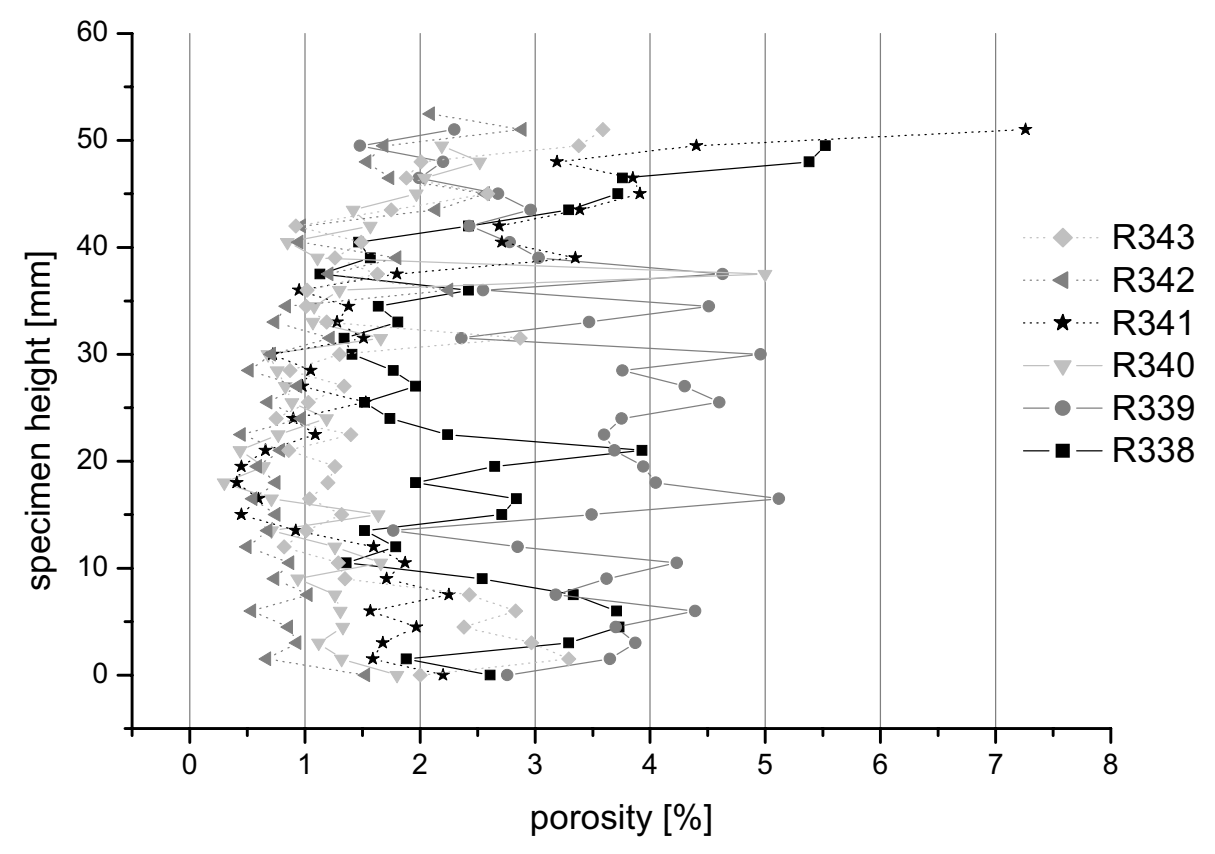

Figure 6. Porosity over spray height of ring 338-342

In this phase the aim was to repeat the defined optimized parameters. The data records of the deposition temperature (Fig. 7) from these trials are showing the capability of the operator and used equipment to repeat these parameter sets with minor deviations. Also the Porosity distribution (Fig. 8) followed the values of the master ring 340 and better. The rings, produced under these optimized condition, where used to evaluate different post processing strategies.

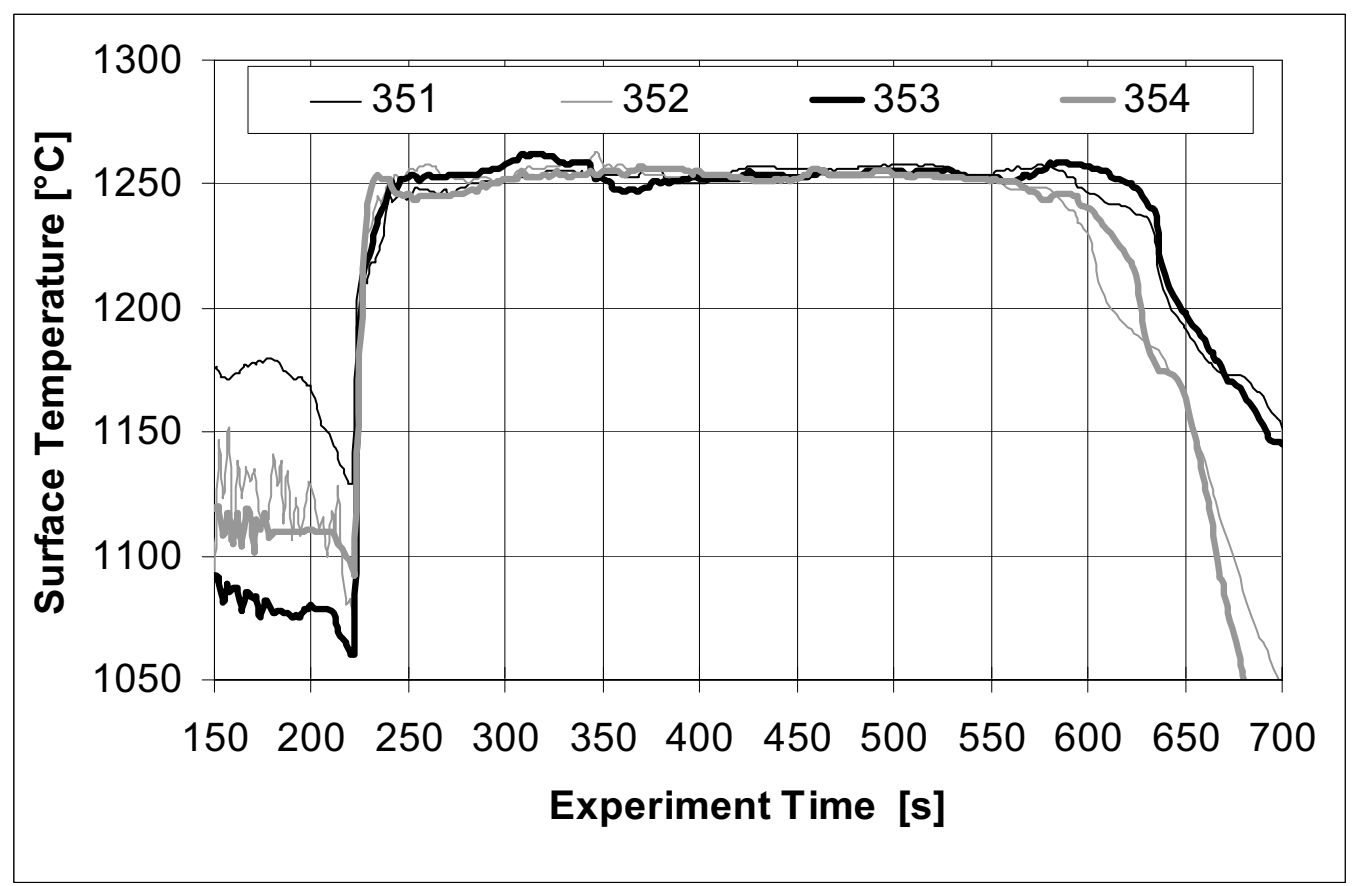

Figure 7. Deposit temperature repeatability trials 


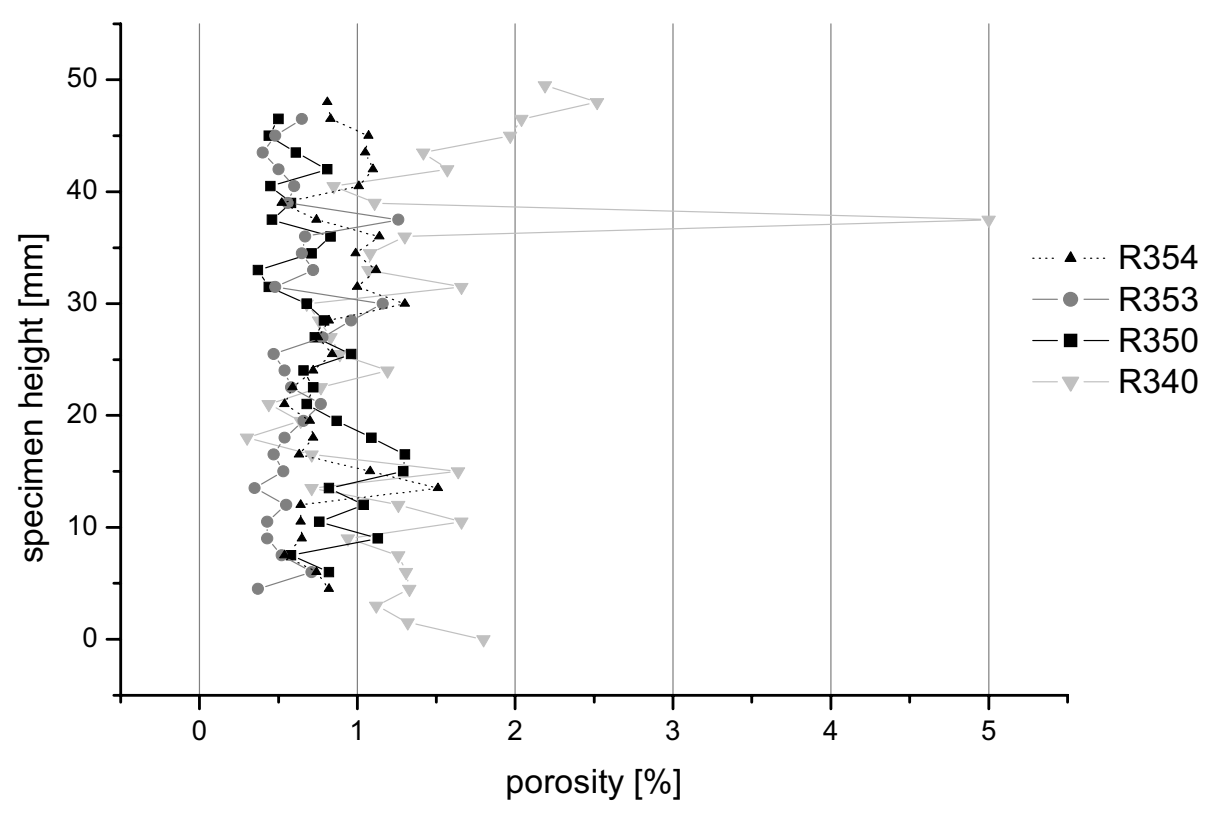

Figure 8 . Porosity over spray height

\section{Evaluation of HIPped structures}

For hot isostatic pressing (HIP) an industrial unit operated at $1140^{\circ} \mathrm{C}$ and $1000 \mathrm{bar}$ pressure under Argon atmosphere was used. Different times on temperature from $3 \mathrm{~h}$ to $6 \mathrm{~h}$ where established. For the IN718 nearly $0 \%$ porosity can be achieved. The difference between 3 and 6 hours is very small as visible in fig. 9.

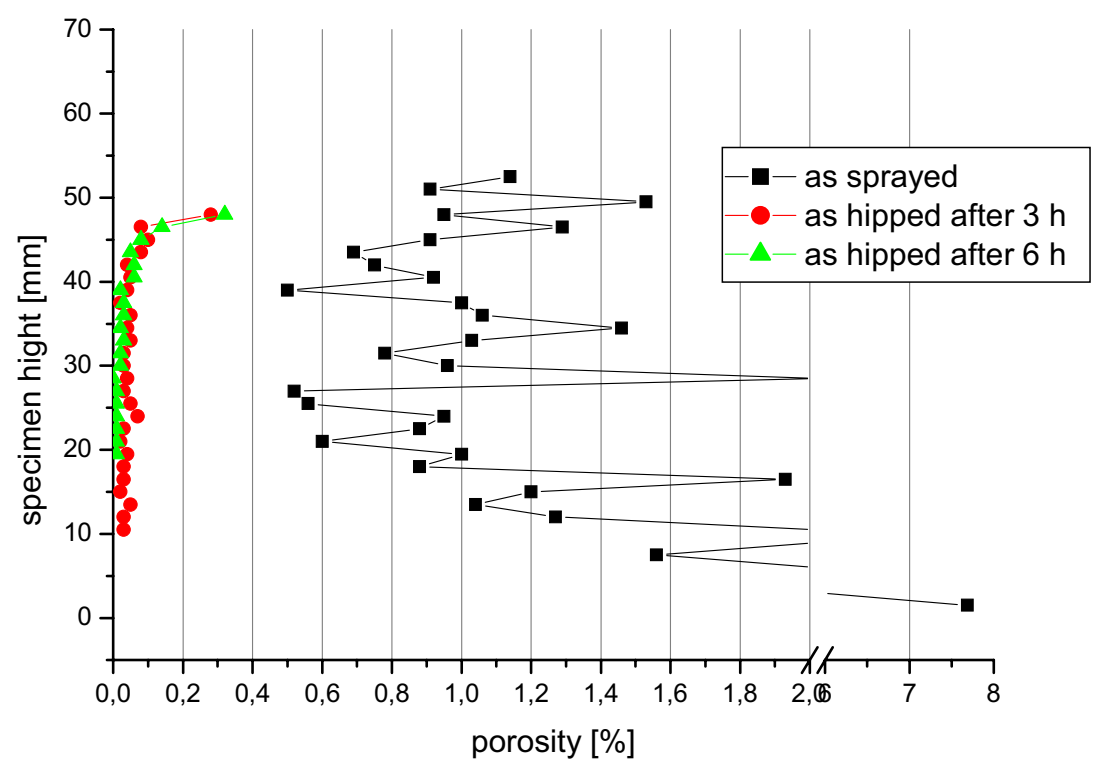

Figure 9. Porosity after HIP-cycles for IN718, ring 307 


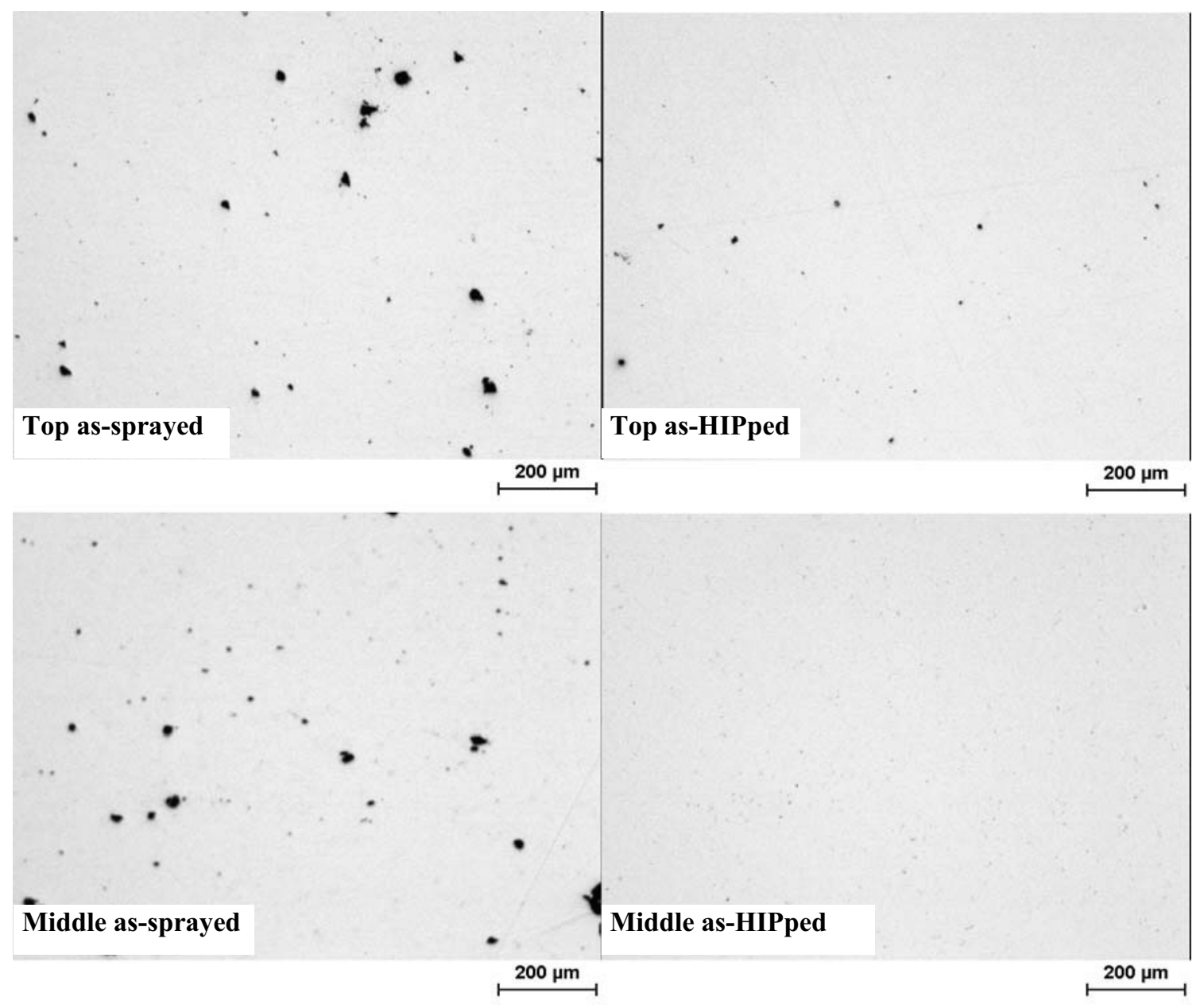

Figure 10. Micrographs of porosity after HIP-cycles for IN718, ring 307

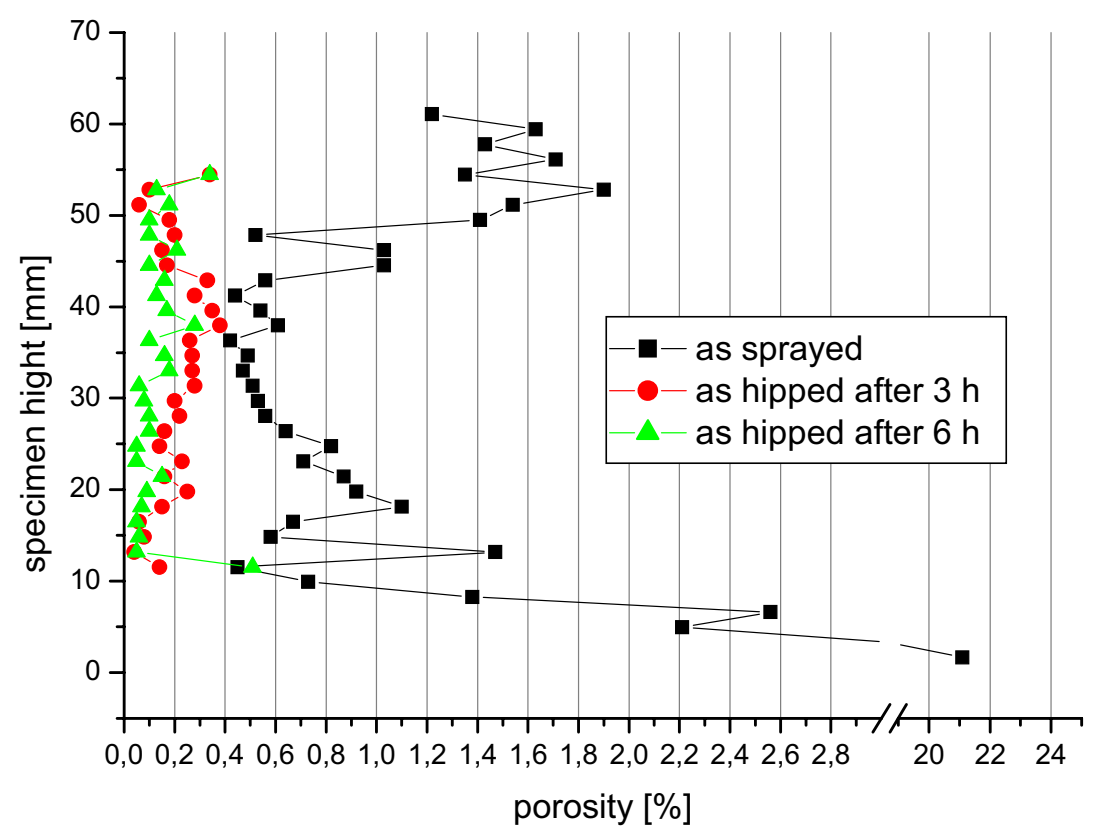

Figure 11. Porosity after HIP-cycles for U720, ring 305 
The porosity of the U720 ring after the same conditions was still over $0 \%$ (Fig. 11, 12). The reason seems to be a temperature shift of the gamma prime precipitations from over $40 \mathrm{~K}$ to higher temperatures, because of the applied pressure. An experimental HIP facility at the University of Munich with higher possible temperatures from $1140^{\circ} \mathrm{C}$ to $1200{ }^{\circ} \mathrm{C}$ was used at the same pressure. Between 1180 and $1200^{\circ} \mathrm{C}$ the precipitation disappear.

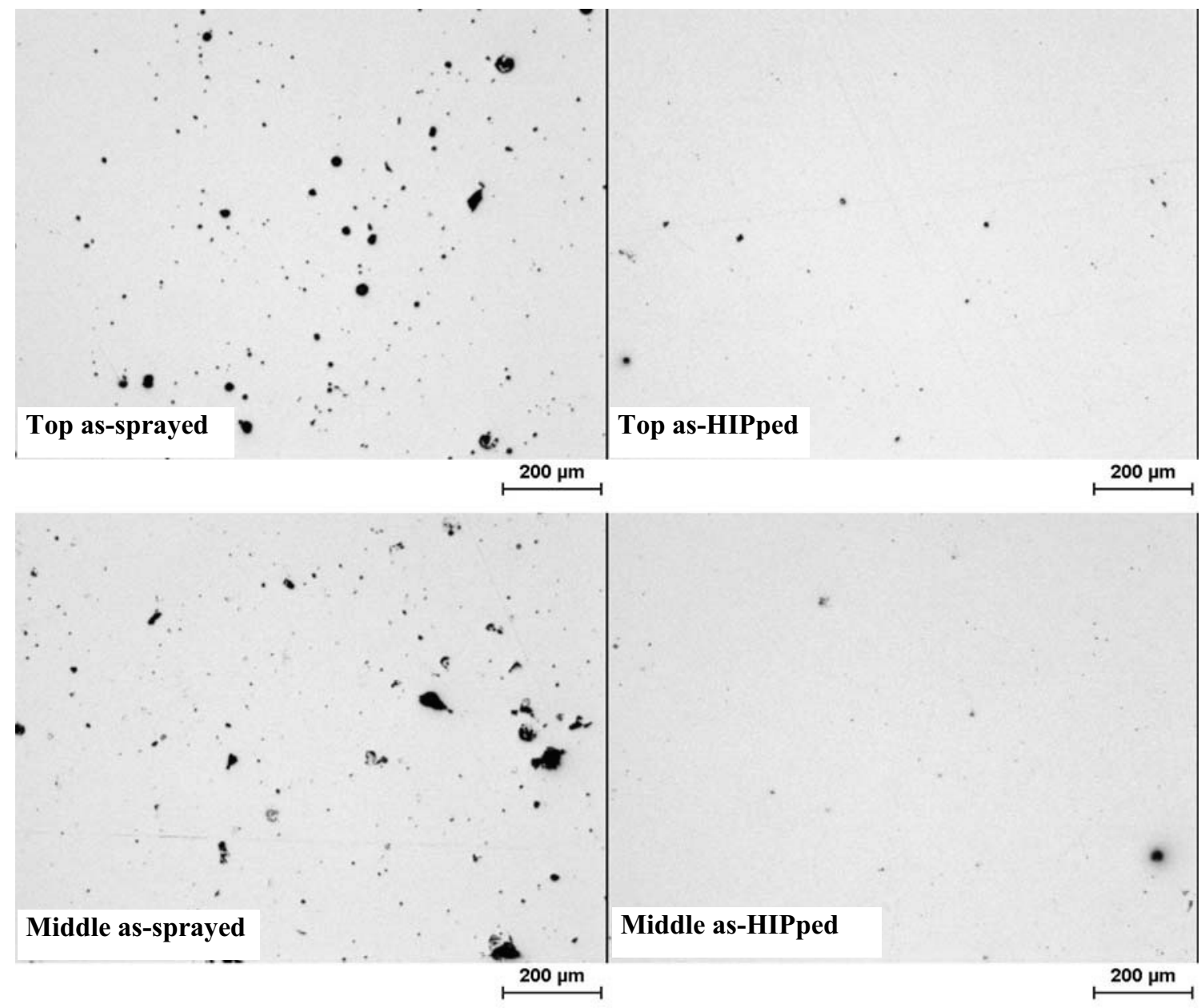

Figure 12. Micrographs of porosity after HIP-cycles for U720, ring 305

\section{Forging of as sprayed and HIPped rings}

To evaluate the optimum post processing route for the optimized sprayed rings several forging experiments on IN718 and U720 material have been performed (Figure 1). The rings in as sprayed or additionally HIPped condition were machined to four quarter rings. The parameters of the thermomechanical processes, which are in accordance with prior experiments and serial production of triple melt material, are listed in Table 2. One thin macro slice was also cut from every ring to analyze macro- and microstructure prior to forging.

Table 2. Forging-parameters of the thermomechanically processed quarter-rings

\begin{tabular}{|l|c|c|}
\hline & IN718 & U720 \\
\hline Forging temperature & $1000^{\circ} \mathrm{C}$ & $1100^{\circ} \mathrm{C}$ \\
\hline Soaking time & $2 \mathrm{~h}$ & $2 \mathrm{~h}$ \\
\hline Ram speed & $10 \mathrm{~mm} / \mathrm{s}$ & $10 \mathrm{~mm} / \mathrm{s}$ \\
\hline No. of heats & 1 & 2 \\
\hline
\end{tabular}


As for normal production a finite element simulation of the thermomechanical process has been performed with the commercial program DEFORM3D ${ }^{\mathrm{TM}}$. In addition to the load-stroke curves the finite element simulation offers additional information about effective strain distribution (Figure 13), temperature and strain rate in the forging. This enables a detailed evaluation of the influence of the before mentioned parameters on the microstructural evolution. Figure 14 shows the forging of an IN718 quarter ring before and after the upsetting.

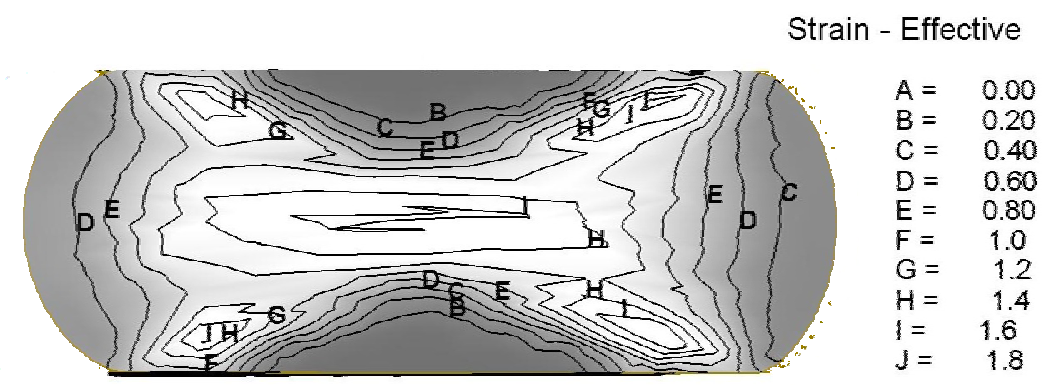

Figure 13. Finite element simulation of the ring forging - effective strain in the cross section in the middle of the quarter ring (DEFORM3D ${ }^{\mathrm{TM}}$ )

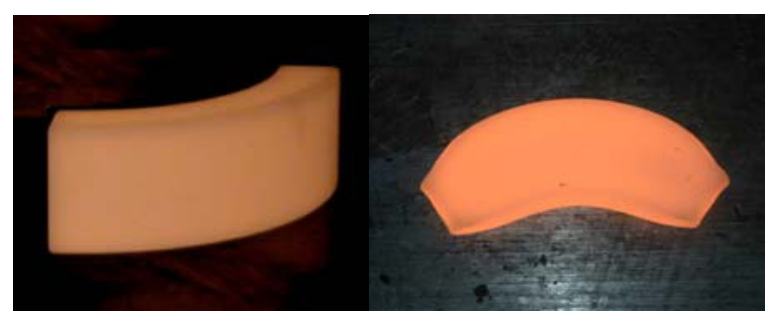

Figure 14. Forging of a quarter IN718 ring on a hydraulic press

The macro (figure 15) and micro analysis (figure 16, 17) of IN718 forged material shows the typical structure of forged pancakes. Depending on the effective strain the grain size changes from the initial coarser grain size, coming from the spray forming process, to finer grains. A minimum strain level of about 0,5 should be reached to guarantee a complete dynamic and/or meta-dynamic recrystallization of the as-sprayed material. In figure 14 the microstructure of a HIPped and forged IN718 ring on different positions is visible. In positions 3 and 4 a recrystallized structure is visible whereas in 2 the recrystallization is not completely finished. Regions 1 and 5, which are poorly deformed, as also visible in figure 13, show a almost unrecrystallized structure. Position 5, which corresponds to the top of the sprayed ring shows a different grainsize as in the bottom region (fig. 15). This is on the one hand due to a slightly lower strain, but on the other hand a reason of a segregation band. The sprayed and forged ring show a very similar macro structure (figure 17) but in the microstructure images (figure 17) on positions with low effective strain or high tensile strain a higher amount of residual porosity is visible. In regions with dominating compression a closing of the pores due to forging is possible. 


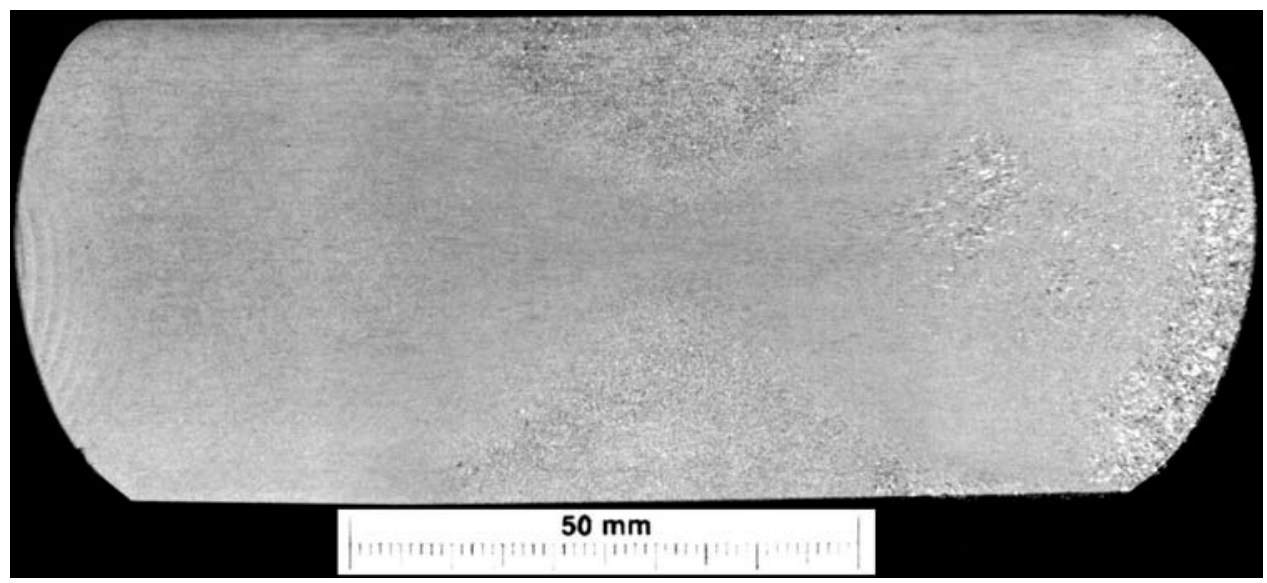

Figure 15. Macro of the cross section in the middle of the HIPped and forged IN718 ring

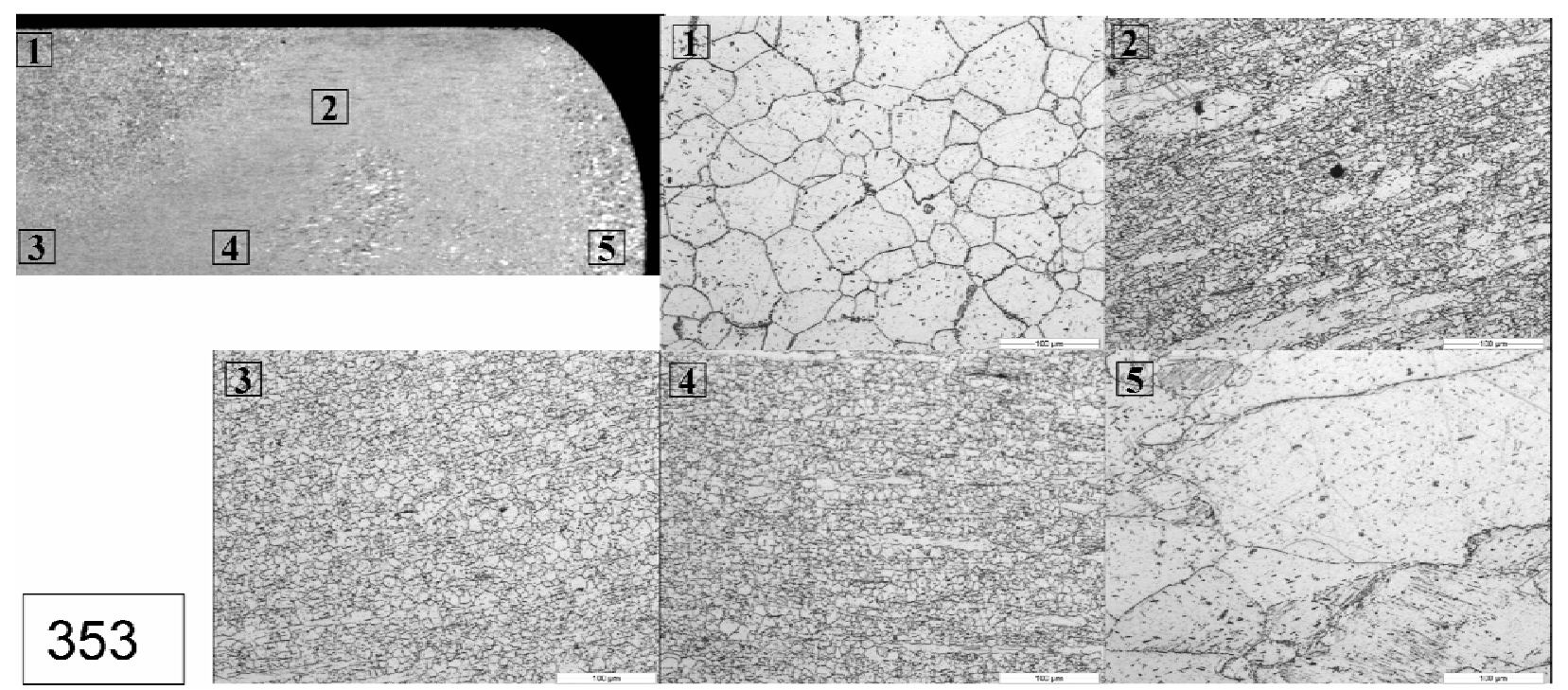

Figure 16. Macro- and selected microstructure images of a HIPped and forged IN718 ring

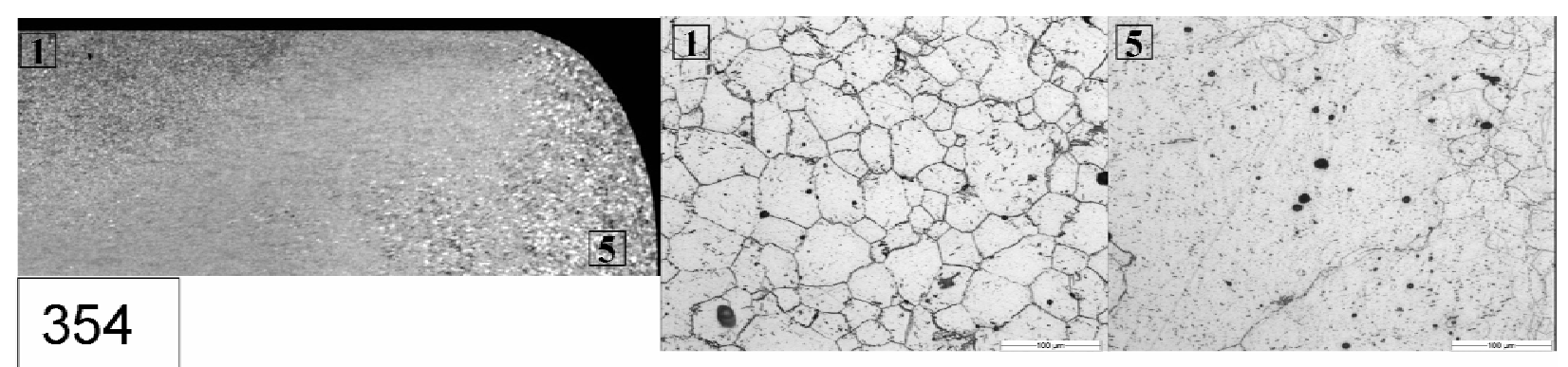

Figure 17. Macro- and selected microstructure images of a forged IN718 ring

The macro and micro analysis of forged U720 samples show small shear bands with a high level of strain and a big area of non deformed material (figure 18). This untypical behavior of U720 during forging is possibly a result of the strong and coarse $\gamma^{\prime}$-precipitations, which couldn't be dissolved during the HIP-process and the heating prior to forging. The slow cooling after the HIPing may also result in a secondary precipitation and coarsening of $\gamma^{\prime}$ particles and lead therefore to an additional hardening of the material. As a complete closing of the pores in U720 was not possible by the performed HIPping cycle, as mentioned before, a fracture-initiation on the surface in combination with the strong shear bands may be the reason for the fold-like shape visible in figure 18 . 


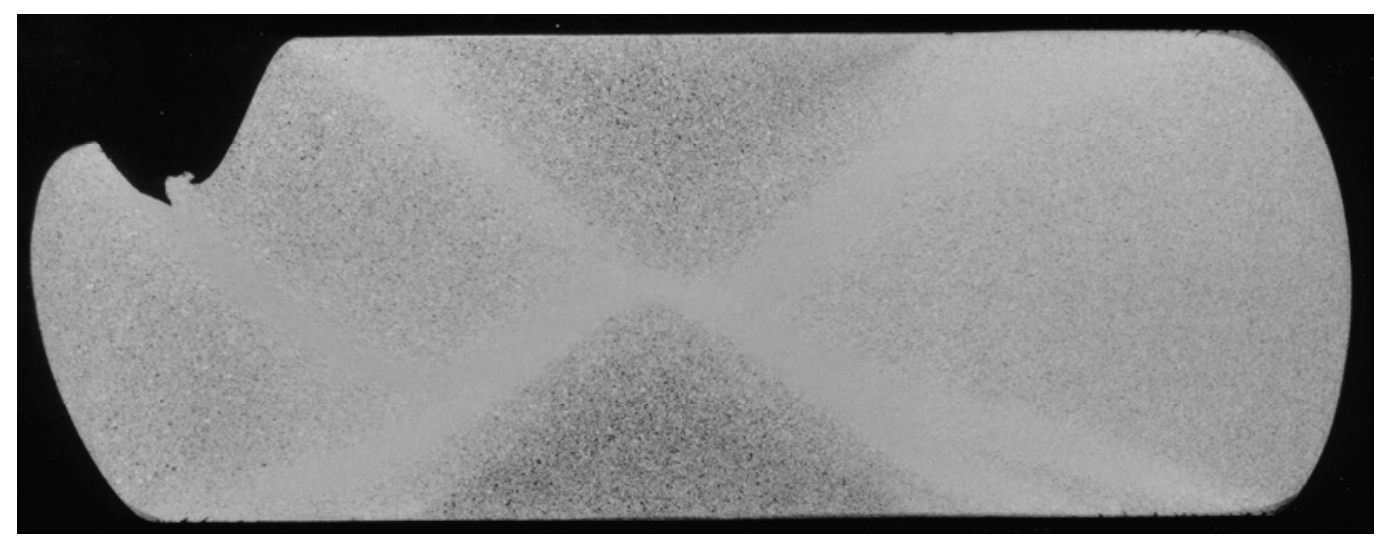

Figure 18. Macro of the cross section in the middle of the HIPped and forged U720 ring

\section{Conclusions}

Super alloy rings IN718 and U720 spray formed using argon and nitrogen as atomizing gas. Using nitrogen for atomization led to an increase in nitrogen content, which was not acceptable. Therefore, argon was used for the optimisation process. After several optimisation steps an average porosity of $0.75 \mathrm{vol} . \%$ was achieved. The porosity was uniformly distributed versus the thickness of the ring and cold porosity in the vicinity of the substrate was avoided due to the preheating of the substrate. A strong correlation between the deposit surface temperature and the porosity with an optimal range between 1240 and $1270{ }^{\circ} \mathrm{C}$ has been established. The reproducibility of the deposit surface temperature was extremely good, which is important to achieve the low porosity. The remaining porosity of the optimized IN718 rings could be closed by HIP with moderate parameters. The same HIP parameters were not sufficient to close the porosity of U720. Forging of as sprayed material also offers a possibility to close pores in regions with high effective strains, whereas regions with low strains still show a significant porosity. HIPped and forged IN718 rings showed the best combination of low porosity and very fine recrystallized grain structure. In case of U720 rings a shift of the $\gamma^{\prime}$-dissolution temperature was observed during HIPping. Due to the resulting precipitation structure strong unfavourable shear bands occurred during forging, thus a higher HIPping temperature must be chosen for further experiments.

\section{Acknowledgements}

The project "Optimisation of Sprayforming of Advanced High Quality Components of Superalloys for Aeronautic Applications" is funded by the European Community under the 'Competitive and Sustainable Growth' Program. All companies and research facilities which are partners in this project are listed in the following table.

Table 3: List of Companies

\begin{tabular}{ll} 
Company & Country \\
\hline Industria de Turbo Propulsores, ITP & Spain \\
\hline Turbomeca & France \\
\hline MTU Aero Engines & Germany \\
\hline INASMET & Spain \\
\hline University of Bremen & Germany \\
\hline University of Oxford & England \\
\hline Böhler Edelstahl & Austria \\
\hline Böhler Schmiedetechnik & Austria \\
\hline ALD Vacuum Technologies & Germany
\end{tabular}




\section{References}

1 A.R.E. Singer, “The Principles of Spray Rolling of Metals", Met. \& Mat., 4 (1970), 246$250,257$.

2 A.G. Leatham and R.G. Brooks, "The Osprey Process for the Production of SprayDeposited Disc, Billet and Tube Preforms", Modern Developments in Powder Metallurgy, 15 (1984), 157-173.

3 R.H. Bricknell, "The Structure and Properties of a Nickel-Base Superalloy Produced by Ospray Atomization-Deposition", Metallurgical Transaction A, 17 (1986), 553-591.

4 H.C. Fiedler, T.F. Sawyer, R.W. Kopp, and A.G. Leatham, "The Spray Forming of Superalloys", Journal of Metals, 39 (1987), 28-33.

5 A.L. Moran, and W.A. Palko, "Spray Forming Alloy 625 Marine Piping", Journal of Metals, (1988), 12-15.

$6 \quad$ R.L. Kennedy, R.M. Davis, and F.P. Vaccaro, "An Evaluation of Spray Formed Alloy 718", Proc. Superalloy 718 - Metallurgy and Applications, (1989), 97-108.

7 V. Uhlenwinkel et al., , Spray Forming and Post Processing of Superalloy Rings “, to be pubished. in Proc. Continuous Casting, (2005)

8 V. Uhlenwinkel et al., "Investigation of Spray Formed Billets from Bearing Steel AISI 52100“, Proc. $4^{\text {th }}$ Int. Conf. On Spray Forming, (1999) 